\title{
Prognostication of concrete constructions durability based on experience in building and exploitation of maritime coast-protecting structures on Sakhalin Island
}

\author{
V.V. Malyuk ${ }^{1, *}$ \\ ${ }^{1}$ LLC Transstroy-Test, Sakhalinskaya St. 108a-22, Yuzhno-Sakhalinsk, 693000, Russia
}

\begin{abstract}
The normative foundations in the field of durability ensuring have been considered. Experience in building and exploitation of hydraulic structures in severe hydrometeorological conditions of Sakhalin Island coast has been analyzed. The results of designing of concrete's durability on the prescriptive base of normative documents are presented. The time period, which can be adopted as estimated lifetime of structures at the designing stage, is proposed. The main reasons of concrete's degradation, observed in the earliest exploitation periods, have been revealed.
\end{abstract}

\section{Introduction}

In recent years the questions of durability of concrete have attracted attention of many experts, calculations of durability of structures become a standard in many countries all over the world [1-3]. The term "durability of structures" used during many years in domestic and foreign practice was a subjective and often difficult to be quantitatively determined. Until the present days there is no any generally accepted method for calculating of concrete and reinforced concrete structures for a longevity. However, with the adoption of such regulatory and legal acts as the Law "On Technical Regulation" and Technical Regulations on the Safety of Buildings and Structures, the legal basis has been founded in the field of ensuring safety of buildings and structures, the requirements to ensuring durability of building projects have been determined. On the base of these laws terms and general ideas have been standardized, the definitions have been given to these ideas, which fill the "durability" term with a concrete meaning [2]. In this connection it is necessary to pick out a number of theses concerned durability. Firstly, the concept of the life cycle of building or structure has been introduced, it is a period during which design, building and exploitation are realized. Principled distinction and importance of this approach to resolving of the problem of ensuring safety, serviceability and longevity lies in the following. If early in the field of building the main persons were designers and builders, then with adoption of the Technical Regulations on the Safety of Buildings and Structures a new person - the operator - has appeared. It is stipulated with the fact, that today the society's attention is paid not only to erection cost, but also to daily increasing cost of their exploitation. However, in present time the regulations, on the

*Corresponding author: mvv.77@mail.ru 
grounds of which requirements of the Technical Regulations have to be realized, are under developing stage. For instance, the normative document on exploitation rules [4-11] has been adopted just in February of 2017. Allotment in the town-planning industry of the operator, who is vested with legal rights, surely requires to correct the approach to ensuring longevity at the stage of design and building. It is known, that main problems, concerned with lowquality design and building, are necessary to be resolving on the exploitation stage. Due to that the Technical Regulations [12-17] obliges explaining in the project documentation the information about exploitation terms of building or structure or their parts with a view to prevent activities deceiving an operator. The operator needs this information for effective arrangement of works on appropriate maintenance of the object. Cost minimization during the specified exploitation period is a basis of operational activities. Exploitation aim is a minimal cost of service life, so at the design stage it is necessary to specify not only the standard time parameters [2] such as estimated lifetime and structure longevity, but also quality characteristics, by means of which when building a construction efficiency will be provided in specified time periods at the exploitation stage [17].

\section{Results}

In the present normative document [2] the concepts for longevity and time parameters during the structure exploitation period are given:

1. durability: ability of building object to keep its mechanical, physical and other properties determined when designing, that ensures its normal exploitation during the estimated lifetime;

2. estimated lifetime: prescribed in the building regulations or design task the period of exploitation of building object by its purpose till capital repairs and (or) reconstruction with provided technical maintenance; estimated lifetime is counted from beginning of object exploitation or renewal of its exploitation after capital repairs or reconstruction;

3. service life: duration of normal exploitation of the building object with provided technical maintenance and repairing work (including capital repairs) till the condition, when its exploitation becomes inadmissible or inexpedient.

It is evidently, that designer is faced with enough difficult task, that can be resolved only on the basis of reliable methods of calculating or prognostication of exploitation periods:

$$
T_{L}=\sum T_{S}^{1}+T_{S}^{2}+\ldots+T_{S}^{n}
$$

$T_{L}$, structure service life (years), $T_{S}$, estimated lifetime (years).

Therefore, estimated lifetime $T_{S}$ is a measure of durability. During the service life period $\mathrm{T}_{\mathrm{L}}$ of a structure there are may be several $\mathrm{T}_{\mathrm{S}}$ time periods. For maritime hydraulic structures it is appropriate to calculate the value of $\mathrm{T}_{\mathrm{S}}$ from the condition of their number minimization during the $\mathrm{T}_{\mathrm{L}}$ service life period, because the feature of maritime hydraulic structures is low repairability and high cost of capital repairs.

In the present time the designing conception in durability has a prescriptive character. There is no normative base to realize the aforesaid requirements of the Technical Regulations [17], allowing reasonably prescribe the requirements to the parameters of a building object, which allow to assuredly provide safe and effective exploitation during the estimated lifetime. According to the adopted classification of hydraulic structures [9] there is no regulation of service life periods for maritime hydraulic structures. The right to assign the service life period belongs to a customer, who can follow the recommendations of the normative document [2], that recommends service life to be appointed no less than 25 years for the structures exploited in maritime environment or follow the experience of construction and exploitation of the ready-built structures. It is known that longevity first of all depend 
on quality of adopted design decisions, which have to be realized in the building process. That is why the approach to assigning the longevity (estimated lifetime) based on intuition and experience, which is used in the present time, will undoubtedly not satisfy an operator.

During the last 60 years the problem of ensuring durability of concrete of the maritime hydraulic structures has being resolved by frost resistance increasing. Process in development of concrete's properties and technology of concrete mix preparation has allowed to work out the fundamental basics of technology of concrete of high frost resistance [4]. Building experience has shown that this trend is effective and of certain interest. The main achievement of the carried out researches became the fact, that the important role of airentraining admixtures in ensuring of high frost resistance has been ascertained. In the second half of the last century these technologies were used when building the maritime structures in the severe climatic conditions of USSR. For the first time they have been used when building the Kola TPS (tidal power station) in 1960 year. Later the systematic researches in freeze-thaw resistance of concrete and longevity of maritime hydraulic structures have being carried out on the Far East in the period of 1970-1990 years [8, 9]. F.M. Ivanov, the famous scientist in the field of researching of concrete's durability in transport constructions, in his work has [1] noted, that the researches undertaken in USSR on the test benches of Kola TPS and Sakhalin scientific researching laboratory of the CSRIB (the Central Scientific Researching Institute of Building) of the Ministry of Transport Construction, have allowed to draw a conclusion, that the problem of creating of resistant concretes for maritime structures has been resolved. Worked-out during many years the techniques of obtaining of concretes with high frost resistance are reflected in the normative documents [7, 12, 14, 15]. Today there are no problems in the field of making of durable concrete even for highly corrosive mediums. It is proved with experience of building and exploitation of hydraulic structures on the shore of Sakhalin Island during last 100 years. Project of maritime hydraulic constructions on Sakhalin Island has two typical time periods. The first period since 1925 till 1945 year is characterized with intensive building of waterfront concrete structures in the South of Sakhalin Island during the Japanese occupation. The waterfront structures have been performed of giant bodies, which have been made with using of the regional materials and traditional technological methods typical for the first half of the last century. The second period begins since the seventies years of the last centuries, when in technologies of concrete making the chemical additives began to be applied with a purpose of improving of concrete's quality indexes and for frost resistance increasing first. In fact, since this time design and practical appliance of technology of concrete of high frost resistance have begun. Within the last 45 years design and building of maritime hydraulic structures on Sakhalin Island have been fulfilled on the base of technical requirements to protection of concrete and reinforced concrete constructions for exploitation period of 50 years $[7,14,15]$. Analysis of concrete condition in the constructions after different exploitation periods shows, that appliance of technological methods of production of concrete of high frost resistance allows making a concrete with more durable surface layer. For example, the tetrapods made for coastprotecting structures of the Vanino-Kholmsk maritime ferry, in main, have no any surface damages after 40 years of exploitation (fig. 1).

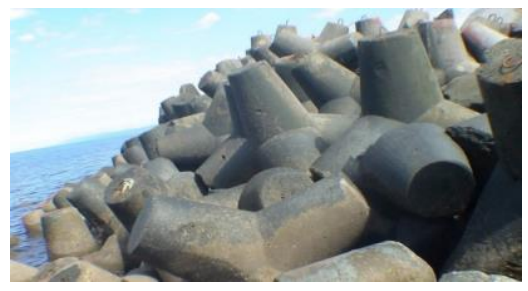

Fig. 1. Condition of tetrapods in a coast-protecting structure of the railway part of the VaninoKholmsk maritime ferry after 40 years of exploitation. 
It is a distinctive feature of this concrete from the constructions made from concrete of traditional technology, where the surface damages are observed on a different depth: from 100 to $300 \mathrm{~mm}$ (fig. 2), in all parts in a zone of variable level.

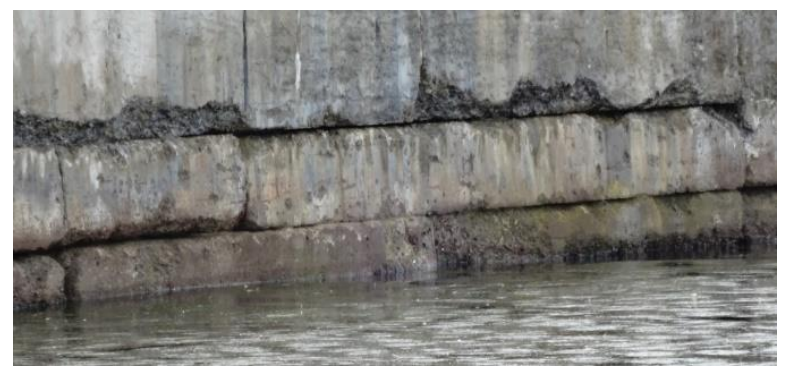

Fig. 2. Condition of the moorage wall in a zone of variable level after 90 years of exploitation (the seaport of Korsakov, Sakhalin Island).

So, the advanced methods of primary protection of concrete and reinforced concrete constructions can provide durability of structures of reinforced concrete no less than 50 years, as concrete surface layer is able to protect armature from corrosion in marine environment. In practice, the concrete structures made by traditional technology can provide durability in a zone of variable level within 100 years, when certain degree of the surface layer damage is tolerated within the exploitation period.

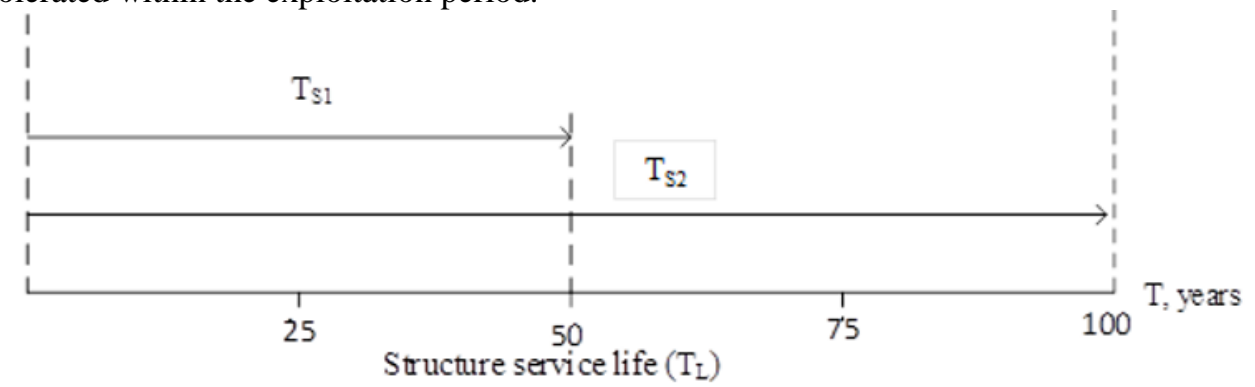

Ts1- estimated lifetime of reinforced structures, made by the technology of concrete of high frost resistance.

Ts2- estim ated lifetime of concrete structures, made by the traditional technology of concrete.

Fig. 3. Recommended estimated lifetimes of maritime structures for exploitation in severe hydrometeorological conditions.

Experience of construction and exploitation of hydraulic structures under the seacoast conditions of the Sakhalin Island, which are classified by hydrometeorological conditions as severe, reveals an ability to provide service lifetime for constructions of concrete within 100 years and reinforced concrete - within 50 years. The researches show, that in accordance with expression (1) the present temporal parameters can be used as estimated lifetime $\mathrm{T}_{\mathrm{S}}$ (fig. 3 ) when maritime structures designing. Concerning these structures there is a full information about concrete, materials for concrete and the technologies of constructions making for these structures [8]. During the structures exploitation periodical inspections are being carried out with the purpose of evaluation of concrete's condition [9]. The results of the carried out researches allowed to mark the significant factors affecting the durability of concrete in the variable level zone, that let us introduce durability as the function:

$$
D=f\left(C_{M} ; C_{B} ; C_{D} ; C_{T} ; C_{N} ; C_{L}\right)
$$


$C_{M}$, the index of quality of the concrete's components, $C_{B}$, the index of the concrete's quality, $C_{D}$, the index of efficiency of the structure-forming additive, $C_{T}$, the index of quality of the technology of concrete making, $C_{N}$, the index of quality of the technology of the construction (product) making, $C_{L}$, the index of quality of concrete's structure.

As evident from the expression (2), the longevity is a complex property depending on a lot of factors. It is necessary to note, that the indexes $\mathrm{C}$ of the expression (2) are complex too:

$$
C=f\left(x_{1} \ldots x_{n}\right)
$$

$x_{1} \ldots x_{n}$, are qualitative characteristics of the materials of concrete or the parameters of technological process.

When ensuring the normative properties of the materials and the parameters of technological processes $(x)$ the indexes $(C)$ in the expression (2) must have the base value equal 1 . Today basis values of the indexes $(C)$ have to be adopted in accordance with working normative documents $[12,14,15]$. Experience in the structures exploitation shows, that it is enough to perform the prescriptive requirements of the normative documents for resolving practical issues of ensuring durability of reinforced structures within 40 years at least. Therefore when $C_{(M, B, D, T, N, L)}=1$, the reinforced concrete structures durability (estimated lifetime) will amount no less than 40 years, i.e. $D \geq 40$. The common idea of durability of concrete and reinforced concrete structures introduced with expression (2) allows to reliably provide estimated lifetime of the constructions, however practical experience in maritime structures building on the Far East within the last 10 years shows, that concrete's failure occurs in the first years of exploitation. The analysis of reasons of durability decreasing shows, that it usually relates to difficulty in estimating the $\mathrm{C}_{\mathrm{D}}, \mathrm{C}_{\mathrm{T}}, \mathrm{C}_{\mathrm{N}}, \mathrm{C}_{\mathrm{L}}$ indexes. Lack of operative and reliable methods of estimating of these indexes results in that after the constructions producing it is impossible to evaluate the durability index. In practice only two $\mathrm{CM}$ and $\mathrm{CB}$ indexes can be reliably, but not operatively, controlled under production conditions. When providing the basis indexes CM, CB CD, CT, CN equal 1 , the key index is a value of CL, that can be evaluated only indirectly by the indexes of concrete hardening conditions: temperature ( $\mathrm{t}$ ), humidity (w) and duration (n). The researches show, that lack of appropriate control of the indexes of structures hardening conditions and requirements to values of these indexes during the process of concrete hardening is a main reason of concrete's failure in the first years of exploitation. If speaking about durability of concrete structures in building of protecting and wave protective constructions on the sea coast of Sakhalin Island, then requirements to separate basis values of the indexes (C) can be less than 1 to provide durability within 100 years, because a possibility of concrete's degradation in the surface layer is allowed without decreasing of operational capability of the constructions. The researches show that the basis values can be decreased, for example, for separate qualitative indexes of a concrete [8,9]. However, the basis values of the $C_{D}, C_{T}, C_{N}$ technological indexes, which substantially determine a value of the $C_{L}$ index, have to be surely provided when producing the constructions.

Because of the lack of data about significance of each $C$ indexes for longevity it is impossible to make a prognosis for durability when $C$ is less than 1 . Observable cases of unexpected failure of concrete at the beginning stage of exploitation, as a rule, are related to inobservance of prescriptive requirements when making and curing of structures, i.e. when the $C_{N}$ and $C_{L}$ indexes are less than 1 . That is why to resolve practical issues it is necessary to ascertain effect of the $C_{N}$ and $C_{L}$ on freeze-thaw resistance. However, now there is no way to do this owing to lack of methods of evaluation of concrete's frost resistance in constructions. So when the $C_{N}$ and $C_{L}$ indexes are less than 1, the probability of prognosis of durability of the real constructions significantly decreases. In accordance with normative requirements [18], the guidelines about methods of control and measurements have to be presented in the project, including the references to the corresponding normative documents. 
Today the instrumental methods of control, allowing evaluation of compliance only on a stage of choosing of materials for concrete and concrete mix, have been worked out. Lack of the methods of estimation the quality of compacted concrete mix by the index of air content and concrete structure's quality does not allow estimating the compliance with project requirements to durability. On the one hand, there are normative documents, which assign the requirements to the indexes of durability, and, on the other hand, there are not any reliable and operative methods to control these indexes for compliance estimation on the stage of construction producing.

\section{Conclusions}

As a result, the constructions are being commissioned without durability indexes. It needs to be referred to the main reason, which does not allow prognosticating durability during exploitation process. Analysis of the maritime structures condition during the process of their exploitation shows, that three typical categories of concrete can be marked: high, normal and low. High category of concrete durability is characterized with lack of surface damages in a zone of variable level within no less than 50 years, normal durability - concrete failure is possible in surface layer with a degradation rate no more than $1 \mathrm{~mm}$ per year, low category is when after first year of exploitation concrete in a surface layer is damaged on a depth more than $10 \mathrm{~mm}$. Under this classification of durability, concrete of normal durability can be used for massive constructions, that allows applying the materials with more low quality indexes in a comparison with a basic and, as a result, the capabilities of a local raw building material base can be used more wide.

Observed cases of concrete failure in a beginning exploitation stage ought to be referred to lack of reliable and operative methods for estimation of the indexes characterizing quality of the constructions producing technology. Due to this, there are the reasons to believe, that working out the methods of estimation of durability indexes of concrete in the constructions is an important line of research in the field of concrete's durability studying and developing of the prognostication methods for the constructions service lifetime.

\section{References}

1. S.N. Alekseev, F.M. Ivanov, S. Modry, P. Shissle, Durability of Reinforced Concrete in Corrosive Environments (Stroyizdat, Moscow, 1990)

2. Russian Federation Standard GOST 27751-2014

3. S.N. Leonovich, Strength of Structural Concrete at Cyclic Freezing-Thawing from the Point of Fracture Mechanics (BrSTU, Brest)

4. F.M. Ivanov, Collection of scientific works ZNIIS 78, 5-13 (1974)

5. V.M. Moskvin, F.M. Ivanov, S.N. Alekeev, E.A. Guzeev, Corrosion of Concrete and Reinforced Concrete, Methods of Protection (Stroyizdat, Moscow, 1980)

6. L.M. Pukhonto, Durability of Reinforced Concrete Structures of Engineering Facilities (ASV, Moscow, 2004)

7. Russian Federation Standard VSN 34-91

8. V.N. Sviridov, V.D. Malyuk, Far East. Scientific works of III All-Russia (II Int.) Conf. on Concrete and Reinforced Concrete, Concrete and Reinforced Concrete - a Look into the Future 3, 388-98 (2014)

9. V.N. Sviridov, V.D. Malyuk, Far East. Incorporated in collected works, Environment. Construction. Safety, 233-236 (2008) 
10. Russian Federation Standard SP 58.13330.2010

11. Russian Federation Standard SP 255.1325800.2016

12. Russian Federation Standard SP 28.13330.2012

13. V.F. Stepanova, V.P. Falikman, Scientific works of III All-Russia (II International) Conference on Concrete and Reinforced Concrete, Concrete and Reinforced Concrete a Look into the Future 3, 430-44 (2014)

14. Russian Federation Standard VSN 118-65

15. Russian Federation Standard VSN 150-93

16. Federal law No. 184-FZ of 27 December 2002 on Technical Regulation

17. Federal law No. 384-FZ of 30 December 2009: Technical Regulations on the Safety of Buildings and Structures

18. Russian Federation Standard SP 48.13330.2011 